\title{
Comparison of Two Electronic Root Canal Length Measurement Devices: The Differences between Ratio Two Impedance Frequencies and Multi Frequencies
}

\author{
Endang Suprastiwi*, Ratna Meidyawati \\ Department of Conservative Dentistry, Faculty of Dentistry, University of Indonesia, Jakarta, Indonesia \\ Email: ${ }^{*}$ esuprastiwi@yahoo.co.id
}

Received 24 March 2014; revised 1 May 2014; accepted 10 May 2014

Copyright (C) 2014 by authors and Scientific Research Publishing Inc.

This work is licensed under the Creative Commons Attribution International License (CC BY).

http://creativecommons.org/licenses/by/4.0/

(c) (i) Open Access

\begin{abstract}
Accuracy electronic root canal length measurement devices were important for root canal treatment. Aim: To evaluate and compare accuracy of the two electronic root canal length measurement devices; two frequencies impedance ratio and multi frequencies. Methods: Forty anterior teeth were sectioned on their cervical area. All samples were measured root canal length by radiographic. On the second phase, all the samples were measured by two frequencies impedance ratio and multi frequencies electronic devices. In the final phase, the teeth were split vertically and actual lengths were measured. All measurement by radiographic and electronic method was subtracted with actual length. Statistical analysis was performed using Chi-square and the Kolmogorov-Smirnov test. Results: Accuracy of the two frequencies impedance ratio $50 \%$ and multi frequencies $47.5 \%$. No statistical significance between two frequencies impedance ratio and multi frequencies. Conclusions: There is no difference between ratio two impedance frequencies and multi frequencies.
\end{abstract}

\section{Keywords}

Electronic Root Canal Measurement Devices

\section{Introduction}

It is generally accepted that root canal treatment procedures should be confined within the root canal system. The success rate could reach up to $90 \%$ - 94\% [1] [2]. In order to achieve the successful root canal treatment, it is

\footnotetext{
${ }^{*}$ Corresponding author.

How to cite this paper: Suprastiwi, E. and Meidyawati, R. (2014) Comparison of Two Electronic Root Canal Length Measurement Devices: The Differences between Ratio Two Impedance Frequencies and Multi Frequencies. Open Journal of Stomatology, 4, 263-267. http://dx.doi.org/10.4236/ojst.2014.45037
} 
important to know the canal terminus which is the limit of root canal and periodontal tissues. There are various methods in determining the canal terminus. Radiographic and electronic root canal length measuring device are often used to measure the root canal length [3]. Radiography is an image of the results of a photographic film irradiated $\mathrm{x}$-ray as it passes through an object on the surface of the radiosensitive. The result of measuring the length of dental radiograph has its limitations because of distortion so as to provide a two-dimensional picture of a threedimensional structure of the tooth with the result that less representative. Due to limitation of the results, the radiographic method was invented an electronic device for the measurement of root canal length. Electronic root canal length measurement device has a more accurate measurement results when compared with the radiographic measurement results [3] [4].

Electronic root canal length measurement device is used to determine the position of the apical foramen which is the meeting point between root canal and periodontal tissues. Root canal dentin and cement area insulator to electric currents. However, on the minor apical foramen, there is a small hole which is the conductive material is electrically connected to the periodontal ligament it is a conductor for electricity. The basic assumption with all electronic length measuring devices is that human tissues have certain characteristics that can be modeled by a combination of electrical components. Since 1962, electronic root canal length measurement device began to be used, but there was no explanation how these devices work. Classifying and describing electronic root canal length measuring device could be based on the generation time of the issuance of such a device [5]. Nekoofar et al. (2006) states grouping based on the operating of the instrument. While the simple device measure resistance, other devices measure impedance using either high frequency, two frequencies or multiple frequencies. In addition, some systems use low frequency oscillation and/or a voltage gradient method to detect the canal terminus [2]. The impedance ratio-based device using two frequencies is independent of the electrolyte liquid in root canals, and according to Jenkins et al. (2001) this device could detect the apical foramen in the range of $0.4 \mathrm{~mm}$ without disturbing existing irrigation fluid [6]. While according Plotino et al. (2006), the accuracy of this device in measuring the length of work is still in the range of $\pm 0.5 \mathrm{~mm}$ from the apical constriction [3].

There have been efforts to further increase the accuracy of electronic root canal length measurement device. One concept was to measure the impedance characteristics using multiple frequencies. This device uses five different frequencies to measure both components (phase and amplitude) impedance at each frequency so then can know the location of the minor apical foramen (apical constriction). This new generation device has some advantages of more accurate measurement because it measures the characteristic impedance using more than two frequencies. Plotino et al. (2006) stated that the precision instrument with five frequencies is $100 \%$ while the device impedance ratio of the two frequencies with accuracy just reached $97.37 \%$ [3].

Based on the background above, this study will compare and test the accuracy between two electronic root canal length measurement devices: two frequencies impedance ratio and multi frequencies with actual tooth length as a reference. The research results can be used as a reference for endodontist to perform a root canal treatment, especially at the stage of working length measurement.

\section{Materials and Methods}

Forty anterior teeth, closed apices with no defect on root surface were used as a sample study. All samples are cleaned up from any calculus or stain then soaked in saline solution until the study perform. All samples included in these criteria were sectioned at cervical area with carbarundum disc and low speed hand piece. Flattened surface at cervical area was used as reference point. Samples were numbered and ready to be measured.

A sample was fixed on imaging plate Digora (Juusula, Finland). Then, sample was exposed with x-ray from bucco-lingual direction. The measurement was obtained from the calculation of the tooth length from reference point to radiographic apex minus $1.0 \mathrm{~mm}$. The result image radiographic was measured with Windows version 2.5 Digora. After that, each sample was embedded in container filled with sponge and $\mathrm{NaCl} 0.9 \%$ solution. The root canal was flooded with $\mathrm{NaCl} 0.9 \%$ solution and then dried with a small cotton pellet. Measuring root canal length with two frequencies impedance ratio devices (Root ZX mini, J. Morita Mfg Corp Kyoto, Japan) was performed using a \#15 K file and entered the root canal until sound beep heard for at least five seconds. Electronic measurement with two frequencies impedance ratio device was recorded. The same way was done by using multi frequencies device (Woodpex I, Guilin WoodPecker Medical Instrument Co. Ltd., Guilin, China). After measuring all samples with electronic device, all samples were vertically split and measured the actual length from reference point to apical constriction with $\mathrm{K}$ file \#15 under 3× magnifying loupe. 
The measurement results of radiographs, two frequencies impedance ratio and multi frequencies device were subtracted with the measurement results of actual length in order to obtain the value of difference. Positive value showed the measurement was more than the actual length. As negative value show the measurement was less than the actual length. Descriptively refer to the Real et al. (2011) that makes three categorical made to determine the accuracy of the measurement results are: categorical $(-):<0.5 \mathrm{~mm}$ (shorter than the actual length of the teeth), (0) $\pm 0.5 \mathrm{~mm}$ (length approaching actual length) and $(+)>0.5 \mathrm{~mm}$ (longer than the actual length of the teeth) [7]. The data obtained was analyzed with Chi-square test $(p<0.05)$ and the comparative test Kolmogorov-Smirnov.

\section{Results}

To assess the accuracy of tooth length measurement, the actual length used as the reference measurement. The result of each method of measurement was calculated the difference from the actual length. The results of the three groups were performed with comparative analysis Chi-square test, and for significance for each group were performed with comparative analysis Kolmogorov-Smirnov. Distribution of number and percentage of samples measured with two frequencies impedance ratio electronic device, multi frequencies electronic device and radiograph can be seen in Table 1 and Figure 1.

The determining of the location of the apical constriction on category (0); two frequencies impedance ratio electronic device present in as many as 20 samples of 40 samples $50 \%$ and electronic device based on multi frequencies were 19 samples from 40 samples $47.5 \%$, while the radiograph measurements were only $5 \%$.

In Table 2, statistic analysis using the Kolmogorov-Smirnov test for the three groups, the value of significance-
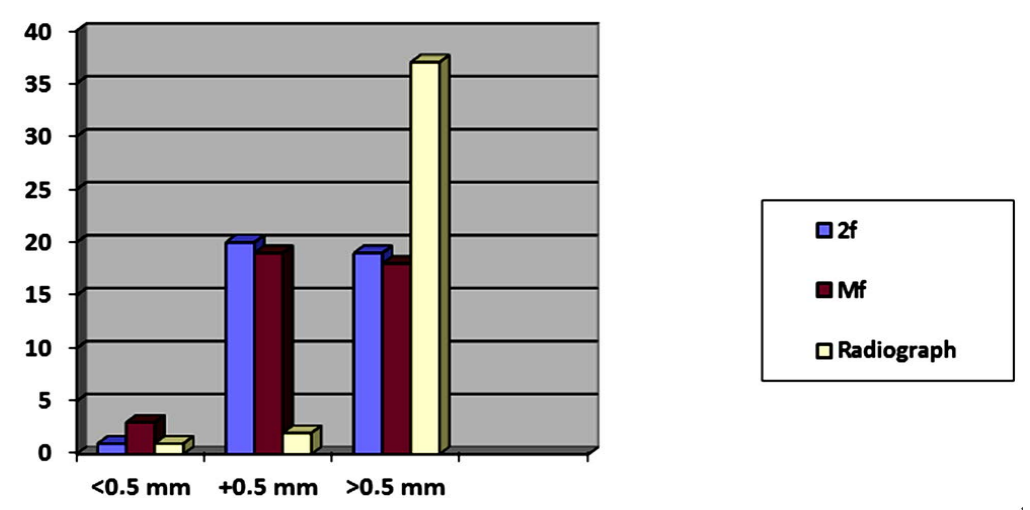

Figure 1. Diagram of the distribution method of measuring the root canal length.

Table 1. Distribution and percentage of electronic and radiographic measurements.

\begin{tabular}{|c|c|c|c|c|c|c|c|c|}
\hline \multirow[t]{2}{*}{ Methods of measurement } & \multicolumn{2}{|c|}{$(-)$} & \multicolumn{2}{|c|}{$(0)$} & \multicolumn{2}{|c|}{$(+)$} & \multicolumn{2}{|c|}{ Total } \\
\hline & $\mathrm{n}$ & $\%$ & $\mathrm{n}$ & $\%$ & $\mathrm{n}$ & $\%$ & $\mathrm{n}$ & $\%$ \\
\hline $2 f$ & 1 & 2.5 & 20 & 50 & 19 & 47.5 & 40 & 100 \\
\hline Mf & 3 & 7.5 & 19 & 47.5 & 18 & 45 & 40 & 100 \\
\hline Radiograph & 11 & 2.5 & 2 & 5 & 37 & 92.5 & 40 & 100 \\
\hline
\end{tabular}

$(-)=<0.5 \mathrm{~mm}$ from actual length; $(0)= \pm 0.5 \mathrm{~mm}$ from actual length; $(+)=>0.5 \mathrm{~mm}$ from actual length; $2 \mathrm{f}=$ Two ratio impedance frequencies; Mf $=$ Multi frequencies.

Table 2. Test of significance between groups.

\begin{tabular}{cc}
\hline Method of Measurement & $p$ Values \\
\hline 2f vs. Mf & 1.00 \\
2f vs. Radiographs & $0.00^{*}$ \\
Mf vs. Radiographs & $0.01^{*}$ \\
\hline
\end{tabular}

*Significantly different, significance analysis by Kolmogorov-Smirnov test. 
$(p)$ between the two frequencies-based electronic devices and multi frequencies-based is $1.000(p>0.05)$. These results illustrate that the two groups did not have a significant difference. As the two groups compared with radiographs there were a significant difference value.

\section{Discussion}

To simplify and uniformity of the sample in this study was used anterior teeth as a sample because they have single root. In order condition of the sample in accordance with the biological situation in the oral cavity, the sample was immersed in saline solution prior to the study. Measurement of the teeth length usually starts from a reference point that is located on the highest tip the crown. For simplify determining location of the reference point, all samples cut perpendicular to the axis of the teeth in cervical area, that it is located a stable reference point [8]. The number of samples used in this study, refer to the Rules of Thumb that suggest the nonparametric-test or multivariate tests on samples that are not given treatment, the number of samples used at least 40 samples [9].

Radiographic measurements performed with parallel technique, because it can get images with the same angle so it can download the picture better visualization [10]. Radiograph measurements done by measuring the distance between the reference point to the apex end. Apical constriction location is determined by subtracting $1 \mathrm{~mm}$ of tooth length measured value. It refers Vieyra et al. (2010) which stated that location of the apical constriction is in position $1 \mathrm{~mm}$ from the radiographic apex end [11].

Tooth length measurement by electronic means using the file $\mathrm{K}$ number 10 or 15 because the maximum tactile sensations tool was available [12]. A length measurement with electronic device is programmed only to the extent of the apical constriction [7]-[13]. Thus electronic root canal length device can only detect the presence of apical constriction. According to Huang (1987) principle of electronic working length device is on electric properties of the tooth itself [14]. To achieve clinical situations, samples were placed in a medium that has an electrical resistance similar to the periodontal tissue. The samples were embedded in saline-soaked sponge that has properties similar to the alveolar bone and fluid [7].

Actual tooth length measurements made from the reference point to the apical constriction. Location of apical constriction was used as the zero point for calculating the difference in measurements with radiographic and electronic methods. The results were then grouped into 3 categorical outcomes: $(0)= \pm 0.5 \mathrm{~mm}$ (near the apical constriction), $(-)=<0.5 \mathrm{~mm}$ (shorter than apical constriction) or $(+)=>0.5 \mathrm{~mm}$ (longer than apical constriction).

The results in Figure 1 and Table 1 indicate that two frequencies electronic device at category (0) has a value of $50 \%$ and $(+)$ has a value of $47.5 \%$, the multi frequencies device at category ( 0 ) has a value of $47 \%, 5 \%$, and $(+)$ has a value of $45 \%$, but the radiographic method at category $(+)$ has a value of $92.5 \%$. It is proved that all three methods of measuring the length of the teeth, radiographic measurement method is a method with the results of the lowest accuracy as it is always longer than the actual length. This result is opposite to the results of Real et al. (2011) who observed the digital radiographic measurements with accuracy of $64.9 \%$. The accuracy of electronic root canal length measurement device in this study is only about $50 \%$ of the value. It can be concluded that the ability of the device to measure the length of the teeth have only limited accuracy rate of $50 \%$ [7].

In Table 2 the three groups were compared, there is significant difference between the two frequency impedance ratio electronic device with radiographic and multi frequencies electronic device with radiographic, whereas if two electronic devices compared there is no significant difference between them. It can be concluded that system difference in the two electronic devices do not affect the accuracy of length measurement. This finding is in agreement with the statement of the manufacturer of electronic measuring devices which stated that the ability of at two frequencies electronic device is $53 \%$ - $74 \%$ accuracy, and the results of research supported by the statement by Javidi et al. (2009) that both two frequencies and multi frequencies electronic measuring device are not affected by the presence of pulp, pus or irrigation fluid. It can be concluded that the electronic root canal length measurement device measuring tooth length cannot be relied a hundred percent accuracy [15].

\section{Conclusion}

The ratio two frequencies impedance root canal length measurement device has same accuracy level with multi frequencies but no significant difference.

\section{References}

[1] Ricucci, D. and Langeland, K. (1998) Apical Limit of Root Canal Instrumentation and Obturation Part 2. A Histologi- 
cal Study. International Endodontic Journal, 31, 399-409.

[2] Nekoofar, M., Ghandi, M., Hayes, S. and Dummer, P. (2006) The Fundamental Operating Principles of Electronic Root Canal Length Measurement Devices. International Endodontic Journal, 39, 595-609. http://dx.doi.org/10.1111/j.1365-2591.2006.01131.x

[3] Plotino, G., Grande, N., Brigante, L., Lesti, B. and Somma, F. (2006) Ex Vivo Accuracy of Three Electronic Apex Locators: Root ZX, Elements Diagnostic Unit and Apex Locator and ProPex. International Endodontic Journal, 39, 408414.

[4] Dimitrov, S. and Dimitur, R. (2009) Sixth Generation Adaptive Apex Locator. Journal of IMAB-Annual Proceeding (Scientific Papers).

[5] Gordon, M. and Chandler, N. (2004) Electronic Apex Locators. International Endodontic Journal, 37, 425-437. http://dx.doi.org/10.1111/j.1365-2591.2004.00835.x

[6] Jenkins, J.A., Walker Iii, W.A., Schindler, W.G. and Flores, C.M. (2001) An in Vitro Evaluation of the Accuracy of the Root ZX in the Presence of Various Irrigants. Journal of Endodontics, 27, 209-211. http://dx.doi.org/10.1097/00004770-200103000-00018

[7] Real, D.G., Davidowicz, H., Moura-Netto, C., Zenkner Cd, L.L., Pagliarin, C.M.L., Barletta, F.B., et al. (2011) Accuracy of Working Length Determination Using 3 Electronic Apex Locators and Direct Digital Radiography. Oral Surgery, Oral Medicine, Oral Pathology, Oral Radiology, and Endodontology, 111, e44-e49. http://dx.doi.org/10.1016/j.tripleo.2010.10.033

[8] Assuncao, F. (2010) Ex Vivo Evaluation of the Accuracy and Coefficient of Repeatability of Three Electronic Apex Locator Using a Simple Mounting Model: A Preliminary Report. International Endodontic Journal, 43, 269-274. http://dx.doi.org/10.1111/j.1365-2591.2009.01674.x

[9] Madiyono, B., Moeslichan, S., Sastroasmoro, S., Budiman, I. and Purwanto, S. (2002) Perkiraan Besar Sampel. In: Sastroasmoro, S. and Ismael, S., Eds., Dasar-Dasar Metodologi Penelitian Klinis, Sagung Seto, Jakarta, 285.

[10] Walton, R. (2008) Diagnostic Imaging A. Endodontic Radiography. In: Ingle, J., Bakland, L. and Baumgartner, J.C., Eds., Endodontics, 6th Edition, People’s Medical Publishing House, 554-557.

[11] Vieyra, J., Acosta, J. and Mondaca, J. (2010) Comparison of Working Length Determination with Radiographs and Two Electronic Apex Locators. International Endodontic Journal, 43, 16-20. http://dx.doi.org/10.1111/j.1365-2591.2009.01620.x

[12] Meredith, N. and Gulabivala, K. (1997) Electrical Impedance Measurement of Root Canal Length. Endodontics and Dental Traumatology, 13, 126-131. http://dx.doi.org/10.1111/j.1600-9657.1997.tb00025.x

[13] Welk, A.R., Baumgartner, J.C., Marshall, J.G. (2003) An in Vivo Comparison of Two Frequency-Based Electronic Apex Locators. Journal of Endodontics, 29, 497-500. http://dx.doi.org/10.1097/00004770-200308000-00002

[14] Huang, L. (1987) An Experimental Study of the Principle of Electronic Root Canal Measurement. Journal of Endodontics, 13, 60-64. http://dx.doi.org/10.1016/S0099-2399(87)80156-5

[15] Javidi, M., Moradi, S., Rashed, R. and Raziee, L. (2009) In Vitro Comparative Study of Conventional Radiography and Root ZX Apex Locator in Determining Root Canal Working Length. The New York State Dental Journal, 75, 48-51. 